\title{
Scholarship in Mathematics Support services
}

\section{Peter Samuels}

Coventry University, UK

\section{Chetna Patel}

University of Sheffield, UK

\begin{abstract}
Mathematics Support is a recognised collective term for a variety of extracurricular mathematics and statistics teaching and learning services and resources provided by many Tertiary Educational Institutions. Typical services currently provided in the UK are described. Even with excellent Mathematics teaching, the authors argue that, in the current UK Tertiary Educational climate, there is still a need for Mathematics Support services. This paper provides evidence of maturity and scholarly practice within the UK Higher Education Mathematics Support community of practice.
\end{abstract}

The definition of scholarship of teaching and learning and its application within this context is discussed. Three areas where scholarship can be demonstrated in Mathematics Support services are identified and explored. Firstly, scholarship in the Mathematics Support community of practice in the UK since the early 1990s is demonstrated through surveys of the extent of Mathematics Support provision. Secondly, scholarly practice in Mathematics Support is explored through case studies of good practice. In particular, a detailed case study of the use of electronic record keeping in Mathematics Support tutoring to improve support effectiveness is provided. Thirdly, the Mathematics Support excellence rewarded by the Centre for Excellence in Teaching and Learning status given to Coventry and Loughborough Universities is investigated. Evidence is provided of scholarship both leading to this award and in developments in Mathematics Support services provided after it was made. This paper concludes by evaluating how far scholarship has gone within the discipline of Mathematics Support and anticipating how the community of practice will develop in the future. 


\section{Mathematics Support: definition and rationale}

Mathematics and Statistics Support is a term used mainly in UK Further Education (FE) and Higher Education (HE) to describe the provision of supplementary forms of teaching and resources for mathematics (including statistics) learning across institutions in addition to the main teaching provision. According to Beveridge (1997) and MathsTEAM (2003: 3), common forms of Mathematics Support are:

- Bridging courses;

- Computer-aided learning;

- Diagnostic testing (normally at university entry, and normally followed by other forms of follow-up support);

- Drop-in centres;

- Workshops;

- Numeracy classes;

- Paper-based open learning materials;

- Peer study support;

- Tutoring;

- Videos;

- Websites (which may also include some of the above types of resources).

Two other important terms here are Mathematics Support Centre and Mathematics Learning Centre: these refer to a drop-in centre room from which other forms of Mathematics Support may also be provided.

The main reason for the emergence of Mathematics Support provisions is the 'mismatch between students' mathematical confidence, knowledge and skills at university entry and those required in order to commence their degree courses' (Lawson et al., 2003: 5). A secondary reason for its emergence is 'the increasing breadth of variation of mathematical and statistical competences of students entering the same university courses'. As lecturers tend to target the average (or slightly below average) student ability, this means that not only 'at risk' students with poor entry skills require supplementary support, but support also needs to be provided for brighter students who are not sufficiently challenged (Croft and Grove, 2006). 
In 2001, the UK Government commissioned the 'Roberts Review' (Roberts, 2002) due to its concern that the supply of high quality scientists and engineers should not constrain the UK's future research and development and innovation performance. The review found a strengthening demand in the economy for highly numerate graduates but also a decline in numbers of mathematics, engineering and physical science graduates which was starting to result in skills shortages. It also found mismatches between school level physical sciences and mathematics courses and undergraduate courses in related subjects (differences in mathematical knowledge was seen to be particularly important) which prevented some students making the transition to HE smoothly. Along with other recommendations it recommended (Roberts, 2002: 93) that the UK Government should 'help students make the transition from A-level study to degree level study in science, engineering and mathematics ... [by] funding HEls to use new 'entry support courses' and e-learning programmes to 'bridge' any gaps between students' A-level courses and their degree courses'. This recommendation corresponds closely with some styles of Mathematics Support described above. It is therefore concluded that there is a requirement for Mathematics Support within UK HE in addition to other strategies for improving the quality of mathematics teaching and learning and thus increasing the supply of numerate graduates.

\section{History of the Mathematics Support community of practice}

Although the existence of Mathematics Support centres in UK HE can be traced back to 1990 (and possibly earlier in FE), the Mathematics Support community of practice (Wenger, 1998) in UK HE only really came into existence through the First National Conference on Mathematics Support hosted by the University of Luton in 1993. This conference provided presentations in the area of Mathematics Support, feedback on the first national survey of mathematics support provision (Beveridge and Bhanot, 1994), and a model of how support might be developed based on the Academic Support Centre at Minnesota College of Education and Human Development (formerly Minnesota General College) (Beveridge, 1993). It also led to the establishment of the Mathematics Support Association which ran from 1993 to 1999 and produced eight newsletters.

Some Mathematics Support Centres, such as those provided at Coventry and Loughborough Universities, were originally set up to support Engineering Mathematics 
teaching. However, many now support mathematics (or numeracy) teaching on a university-wide level - see Lawson et al. (2003: 5) for a rationale. This historical association with Engineering Mathematics may also explain the greater emphasis on Mathematics and the lesser emphasis on statistics within the discipline. Whilst statistics support has generally been provided within Mathematics Support centres, statistics was generally not perceived as a subject requiring a specialist approach until 2005 with the emergence of Statistics Advisory Services as part of the strategy of the sigma Centre for Excellence in Teaching and Learning. With the demise of the Mathematics Support Association in 1999, publications in Mathematics Support mainly switched to the Learning and Teaching Support Network (LTSN - now superseded by the Higher Education Academy) subject centre in Mathematics, Statistics and Operations Research (MSOR) Network's professional newsletter: MSOR Connections.

In 2004, the LTSN funded the development of mathcentre - a website providing a variety of types of integrated resources for students in the transition from school to FE or HE, some of which are contextualised (Croft and Stevenson, 2004). About the same time, the Higher Education Funding Council of England (HEFCE) Fund for the Development of Teaching and Learning, the Gatsby Foundation and the EBS Trust jointly funded mathtutor. Originally distributed on DVD, this is now a website based around streamed videos which teach generic mathematical subjects. Both these sites - mathcentre and mathtutor - have become extremely popular, both nationally and internationally, with mathcentre receiving up to 330,000 hits per month (Lawson et al., 2009).

From 2002 to 2005 HEFCE and the Higher Education Academy (HEA) funded a project called Helping Engineers Learning Mathematics (HELM). This Project produced a website and resources that were released to the UK HE community (Harrison et al., 2006) comprising of paper-based student workbooks, electronic versions of the workbooks, a databank of formative and summative computer assisted assessment questions and short video clips showing lecturers solving problems linked to workbooks. Since 2005 the HELM Project and the MSOR Network in conjunction with the sigma CETL have run an annual national conference known as CETL MSOR which has grown in size and quality with increasing emphasis on more rigorous educational research rather than mathematics lecturers' 'show and tell'. 


\section{Definition of scholarship in Mathematics Support}

It is generally accepted that the contemporary concept of the scholarship of teaching was first introduced by Boyer in his 1990 report for the Carnegie foundation (Boyer, 1990). His report enabled the scholarship of teaching and learning to be elevated to the status of a legitimate research field on a par with three other areas of scholarship he identified: subject specific research, synthesis, and professional practice. Kreber (2002) reviews the development of the concept of the scholarship of teaching over the previous 10 years and defines scholars of teaching as expert teachers who 'share their knowledge and advance the knowledge of teaching and learning in the discipline in a way that can be peer reviewed'.

A major emphasis of the scholarship of teaching and learning community is therefore the gathering of evidence of some form of teaching or learning enhancement from a wide variety of sources. This article thus provides some specific examples of excellent practice in Mathematics Support. Furthermore, in line with Kreber's definition, the systematic communication of excellent practice in Mathematics Support is also discussed by investigating the provision of a good practice guide and an accredited training course.

Healey (2000) argues for the importance of a discipline-based approach to the scholarship of teaching in $\mathrm{HE}$ in which scholarship of teaching within the community representing the discipline is provided as well as scholarship of teaching within the subject itself. As the Mathematics Support community within individual institutions is generally very small, a discipline-based approach within Mathematics Support needs to be organised at the level of the national community of practice. One way this community has presented itself as a professional research community is by carrying out a number of surveys into the extent of provision in UK FE and HE. A meta-analysis of these surveys and others outside of the UK is here provided.

A final area in which scholarship in Mathematics Support is explored here is the HEFCE award for the sigma Centre for Excellence in Teaching and Learning (CETL) in Mathematics Support given to Coventry and Loughborough Universities. CETLs were rewarded for their good practice in order to elevate them further as 'beacons of good practice' within the UK HE sector (Saunders et al., 2007). sigma's strategy to elevate and improve good practice has involved pedagogical research into teaching and learning 
effectiveness within Mathematics Support (Samuels, 2006). This strategy is closely linked with scholarship in teaching and learning as it involves both good practice and its dissemination within an academic community. Evidence of good practice within sigma is provided from the original bid document and the formative evaluation of the CETL.

\section{Surveys into the extent of Mathematics Support provision}

The first kind of scholarly activity undertaken by the Mathematics Support community of practice explored here is the carrying out and reporting on surveys into the extent of provision. A summary of the published surveys into the extent of the provision of Mathematics Support in UK FE and HE is shown in Table 1. Of these, the surveys of Beveridge (1997) and Perkin and Croft (2004) were the most thorough in terms of using several forms of inquiry and attempting to approach several people at each institution. From these two surveys it is concluded that at least $50 \%$ of all UK HEls had a Mathematics Support drop-in workshop or drop-in centre at the time they were questioned. 
Table 1. Published surveys into UK FE and HE Mathematics Support provision.

\begin{tabular}{|c|c|c|c|c|c|}
\hline Investigator(s) & Date & Reference & Type & Scope & $\begin{array}{l}\text { Proportion } \\
\text { offering a } \\
\text { drop-in } \\
\text { workshop } \\
\text { or support } \\
\text { centre }\end{array}$ \\
\hline $\begin{array}{l}\text { Beveridge and } \\
\text { Bhanot }\end{array}$ & 1993 & $\begin{array}{l}\text { (Beveridge } \\
\text { and } \\
\text { Bhanot, } \\
\text { 1994) }\end{array}$ & Questionnaire & $\begin{array}{l}800 \text { FEIs and } \\
\text { HEls } \\
\text { contacted } \\
\text { with } 100 \text { FEIs } \\
\text { and } 42 \text { HEls } \\
\text { replying }\end{array}$ & $76 \%$ \\
\hline Beveridge & 1996 & $\begin{array}{l}\text { (Beveridge, } \\
\text { 1997) }\end{array}$ & $\begin{array}{l}\text { Telephone and } \\
\text { postal surveys }\end{array}$ & $\begin{array}{l}\text { Replies from } \\
150 \text { HEls and } \\
50 \text { FEls }\end{array}$ & $56 \%$ \\
\hline Beveridge & 1999 & $\begin{array}{l}\text { (Beveridge, } \\
\text { 1999) }\end{array}$ & Not stated & Not stated & $77 \%$ \\
\hline $\begin{array}{l}\text { Lawson, Halpin } \\
\text { and Croft }\end{array}$ & 2001 & $\begin{array}{l}\text { (Lawson et } \\
\text { al., 2001, } \\
\text { 2002) }\end{array}$ & $\begin{array}{l}\text { On-line } \\
\text { questionnaire }\end{array}$ & $\begin{array}{l}\text { Replies from } \\
95 \text { HEls }\end{array}$ & $48 \%$ \\
\hline $\begin{array}{l}\text { Perkin and } \\
\text { Croft }\end{array}$ & 2004 & $\begin{array}{l}\text { (Perkin and } \\
\text { Croft, } \\
\text { 2004) }\end{array}$ & $\begin{array}{l}\text { Email and } \\
\text { telephone } \\
\text { survey }\end{array}$ & $\begin{array}{l}\text { Replies from } \\
101 \text { HEls }\end{array}$ & $65 \%$ \\
\hline
\end{tabular}

Mathematics Support is not limited to the UK. The community of practice in Australia and the Republic of Ireland has reached a sufficient level of maturity to carry out and publish surveys into their levels of provision. MacGillivray (2008) reports that 32 of the 39 universities in Australia have some form of mathematics learning support. Gill et al. (2008) report there were 13 tertiary mathematics support centres in the Republic of Ireland. 


\section{Good practice in the provision of Mathematics Support}

In 2003 the LTSN funded a project to produce guidelines of good practice in the provision of Mathematics Support centres based on the expertise of experienced practitioners (Lawson et al., 2003). These include factors to be considered when providing Mathematics Support, the overall aim and nature of the support need or drivers, physical location of site, staffing and resources, engaging students, funding for the services and evaluation. A recent example of good practice by Loughborough University is the introduction of a Postgraduate Certificate in Mathematics Support and Dyslexia/Dyscalculia in HE/FE (Loughborough University, 2007). This is a British Dyslexia Association accredited programme and addresses how best to support students with specific learning difficulties. However, the development of this advanced provision in the training of specialist Mathematics Support tutors highlights the general lack of provision of non-specialist (i.e. not specifically for dyslexia and dyscalculia) training of Mathematics Support tutors in UK HE. The authors are not aware of any UK HEI currently providing formal non-specialist training to its Mathematics Support tutors, although this is mitigated by the general lack of subject-specific teacher training for Mathematics lecturers in UK HE, which has only recently begun (Cox, 2007).

\section{Evidence of scholarship in Mathematics Support provisions}

There are several sources of evidence into the effectiveness of various types of Mathematics Support provision. These are summarised here.

The first published article known to the authors was by Beveridge (1994) in which he investigated the influence of attendance at drop-in workshop sessions on the percentage of assignments submitted and performance in these assignments for Level 0 Access Numeracy students at the University of Luton. He discovered a positive correlation between workshop attendance and the percentage of assignments submitted (see Table 2) but not with examination performance. The latter was explained by the relative ability of students who attended the drop-in workshops being lower than average (indicating that the workshops were being used mainly as a remedial service). 
Table 2. Attendance of drop-in workshop sessions and \% of students completing all tasks by Level 0 Access Numeracy students at the University of Luton.

\begin{tabular}{|l|l|l|}
\hline Workshop attendance & No. students & \% students who turned in all tasks \\
\hline Never went & $125(46.6 \%)$ & $53 \%$ \\
\hline At least 1 visit & $141(53.4 \%)$ & $78 \%$ \\
\hline At least 5 visits & $33(13.2 \%)$ & $100 \%$ \\
\hline
\end{tabular}

In 2002, MSOR funded case-study research into the provision of Mathematics Support in the UK (MathsTEAM, 2003). This report describes 25 case studies, some of which include evidence of scholarship in their provisions, for example:

- Ellis (2003) reports an individual student describing their Study Support Centre as:

The place to come and ask your stupid questions and get a proper answer, rather than asking your lecturers and getting the 'well really you should know that'. Brilliant.

- Booth (2003) reports that their Learning Resource Centre receives approximately 18,000 visits per year and was commended by the QAA Visiting Panel in a Teaching Quality Assessment.

- Staddon and Newman (2003) report that the number of visits received at their Education Drop-In Centre has increased steadily each year since it was opened and the responses to their annual questionnaire indicate a high level of student satisfaction with their service.

- Coleman (2003) reports on a questionnaire which was administered to all students who receive pre-university paper-based support resources. Approximately $75 \%$ of students responded, all of whom stated that they had worked through at least some of the materials provided and found them easy to use. More than half of the respondents requested for similar resources to be provided in other areas of mathematics. A similar number stated that they had found the drop-in Maths Support provided during the introductory week to be useful. 
A more recent evaluation of scholarship in Mathematics Support practice was carried out by Dowling and Nolan (2006) in which they analysed the effect of attendance at Mathematics Support sessions on the pass rates of 'at risk' students at Dublin City University (see Table 3).

Table 3. Effect of attendance of Mathematics Learning Support Centre sessions on pass rates for 'at risk' students at Dublin City University in 2004/5 and 2005/6.

\begin{tabular}{|l|l|l|}
\hline Year & $\mathbf{2 0 0 4 / 5}$ & $\mathbf{2 0 0 5 / 6}$ \\
\hline No. 'at risk' students & 80 & 161 \\
\hline No. 'at risk' students who visited MLSC & 41 & 95 \\
\hline Pass rate of 'at risk' students who visited MLSC & $53 \%$ & $60 \%$ \\
\hline Pass rate of 'at risk' students who did not visit MLSC & $25 \%$ & $49 \%$ \\
\hline
\end{tabular}

They discovered that attendance of one or more mathematics support sessions increased the pass rate of students by $28 \%$ in $2004 / 5$ and by $11 \%$ in $2005 / 6$.

Bamforth et al. (2007) discuss the effectiveness of various mathematics support provisions for Electrical Engineering students at Loughborough University from non-traditional backgrounds (in terms of their entry qualifications). The number of attendances made by these students at a 30 minute action plan meeting, a one hour lunchtime workshop, or a visit to the Mathematics Learning Support Centre's drop-in service were recorded against diagnostic test mark and final exam mark. They discovered that repeated attendance at mathematics support had a positive effect on examination performance.

Pell and Croft (2008) investigated the number of drop-in support sessions attended by over 600 Engineering students at Loughborough University in 2004/5 and the effect of attendance on their examination grades. They discovered that about $20 \%$ of students used the support centre but it was being used more by higher achieving students than by those who were at risk of failure. They also discovered that, on average, attendance of at least one session in the mathematics support centre led to an improvement in pass rate of approximately $3 \%$. 


\section{Detailed case study of scholarship in record keeping}

An example of scholarship in investigating good practice in Mathematics and Statistics Support is the development of an electronic record keeping (using an MS ACCESS database) of student usage of support - see Figure 1. The purpose of the database is twofold: first to enable analysis of effectiveness of support and secondly to enable reflective and collaborative teaching practice.

The effectiveness of the support provided can be explored using the database by comparing the students' diagnostic test results at entry against their module results and usage of support facilities. The database provides an easy means of collecting usage date including support details and frequency of use. Running queries to select key variables allows a quick and reliable set of data for analysis.

Research using such a data set has shown that HE students can be helped to achieve on their main course by the provision of contextualised additional study support (Patel and Little, 2006). The study analysed a data set of over 20,000 records with about $10 \%$ of students who had made use of mathematics support. The chi-square test carried out on module results gave a significant result (sig. < 0.0005) with a greater proportion $(92 \%)$ of maths related module passes associated to mathematics support users than with the nonmathematics support users (88\%). The independent samples t-test on the module mean scores also showed a better performance $(p=0.01$, sig. $<0.0005)$ by mathematics support users $(60 \%)$ than the non-users (56\%). 
Tutor:

Students:

: AI\&Robotics 3rd Yr- needs help with maths.Ph:

Module Title:

Session: $2005-2006$

\begin{tabular}{|c|c|c|c|c|c|}
\hline Date & Site & $\begin{array}{l}\text { Duration } \\
\text { In hours }\end{array}$ & Topic & $\begin{array}{l}\text { Analytical Reflection } \\
\text { Record any critical incident, any relevant } \\
\text { obsenations, your feeling and/or students' } \\
\text { feelings. Provide an analytical reflection of } \\
\text { how the session went and thoughts on how } \\
\text { you wish to use the infomation or } \\
\text { feedbad from the teaching situations to } \\
\text { improve students' learning, as well as } \\
\text { enhance your professional practice }\end{array}$ & Action required/taken \\
\hline
\end{tabular}

Figure 1. Example of a student log within the database.

The database includes an easy means of completing teaching logs to allow tutors to review and reflect on their practice (Atherton, 2005). The intention of the database is to make 'writing-up' of sessions easier and, more importantly, if used deliberately can enable a cyclic approach to developing and improving teaching methods. This approach is currently being developed for implementation at the University of Sheffield. Reflective logs/journals have been used by educators as a means of facilitating reflective practice where problems and issues in teaching methods can be considered (Kahn et al., 2006: 1317). Support tutors seek to keep up with and research their particular discipline expertise and transfer this into their teaching. This way they are able to communicate the subject matter clearly, provoke enthusiasm, stimulate thinking and challenge the student's intellect (Entwistle, 2009; Thomas, 1993).

The tutors at Mathematics Support centres are under pressure to accomplish a multitude of tasks; it can be easy to feel one has achieved enough for a student by simply providing reassurance and confidence, and provoking motivation for study. Identifying problems with the session and thinking about ways of improving approaches requires time. The database allows for this consideration as tutors collect and input general information about the session (for example time, topic) and additionally a more reflective and analytical prose of 
the session noting any critical incident(s), the students' and tutors' feelings, things that went well, any issues or challenges, what was learned and action required, how to improve practice and performance. The teaching logs give the tutors an opportunity to reflect on the students' initial needs and how these were met over a few appointments, whereby the objectives of teaching can be thought about and delivered proactively. The teaching log also provides the opportunity for team teaching; whereby one student can be seen by a number of tutors and still have reasonable continuity. However, one drawback in maintaining a teaching log in the Maths Support environment where teaching takes place individually or in small groups, is that of efficiency. Writing-up on a short 5 minute drop-in session can become cumbersome and impossible to reflect on with any deep meaning because of time constraints and a lack of opportunity to continue developing the teaching approach in that situation i.e. teaching a student for 5 minutes (maybe just that one time) and spending more than 10 minutes to reflect on feelings and issues to extract meaning.

\section{The sigma Centre for Excellence in Teaching and Learning}

In 2005, HEFCE made a massive investment in teaching and learning in UK HE through the 5 year Centres for Excellence in Teaching and Learning (CETL) programme (HEFCE, 2004). One of the 74 successful bids was the sigma CETL in University-Wide (i.e. both specialist and non-specialist) Mathematics and Statistics Support, based at Coventry and Loughborough Universities. Most developments in Mathematics Support in UK HE since 2005 have taken place through sigma. Its main aim is move the balance from reactive to proactive activities in order to start to address the problems for the mass of students in need. Its activities are being underpinned by a systematic programme of educational research (Samuels, 2006). sigma has made a substantial investment to enhance existing provision in the two host universities and to address proactively the needs of those who can benefit from the support available. Its activities include:

- Extended and enhanced drop-in centres at the two universities;

- A Statistics Advisory Service offering individual Statistical Support for final year project students and postgraduate students (Smith and Gadsden, 2006);

- Support provision for students with special educational needs (Trott, 2003); 
- A Proactive Teaching Programme comprising of several Mathematics teaching interventions at both universities which target 'at risk' students within large cohorts (Lawson et al., 2006); and

- An investigation and development of innovative uses of technology in Mathematics Support, such as the use of mobile devices and educational computer games, known as serious games (Hu and Samuels, 2007).

\section{Evidence of scholarship in sigma}

The original CETL bid document by Coventry and Loughborough Universities (Loughborough University Mathematics Education Centre and Coventry University Mathematics Support Centre, 2004) contains evidence of existing excellent practice, including quotes from students who used the support centres, paper-based resources and websites:

Having just completed the Certificate in Maths l'd just like to comment on what an excellent facility I found the Maths Support Centre to be. ... The assistance provided was always excellent. The printed handouts are very useful too.

I've managed to avoid maths for a long time but your [web] site has given me confidence, and a great deal of revision aids! Thank you for being available. Without you I wouldn't have got the grade that I have just received. Keep up the good work and brilliant site.

An interim internal evaluation of the sigma CETL was carried out in 2007 (sigma Centre for Excellence in Mathematics and Statistics Support, 2007). Whilst Lawson et al. (2006) reported that the findings of the Proactive Teaching Programme were mixed, a number of these interventions received positive reviews from their departmental module leaders evidencing their effectiveness, including a Human Sciences intervention:

Just to give you some updates. Last year was the first year that nobody failed [this module] (as far as anybody can remember this is a first!) so I think that is on its own evidence of the value of the support you provided. In addition I recently received the 
student feedback questionnaires and there were several that had extremely positive comments about the support you provided.

The programme is seeking to identify and build on the strengths of these individual successful interventions.

Finally, the sigma evaluation report also included a quotation from the manager of the MSOR subject centre on the influence of sigma to the whole UK HE Mathematics Support community:

There is also established and ever growing evidence that sigma is having a substantial impact upon the level and nature of mathematics and statistics support offered to students from across the whole of the UK. The model of mathematics support pioneered by sigma has been widely adopted within HEIs across the UK, and it is clear that these HEls are further developing the 'sigma model' and tailoring it to their specific needs.

\section{Conclusions}

The requirements for Mathematics Support within UK HE identified within the introduction are well researched and likely to increase in the future as the need for individual or specific Mathematics Support increases with the average lowering and increasingly diverse mathematical ability of the UK HE student intake. It is anticipated that the Mathematics Support community will continue to respond proactively in developing and sharing support service approaches and resources.

This paper provides evidence of a growing body of research into scholarship in Mathematics Support in UK HE and beyond through surveys, evaluations and dissemination of good practice, in particular the activities of the sigma CETL. All those provided have generally shown positive benefits to students of Mathematics Support services and resources, such as popularity, satisfaction and improved performance in examinations. 
In particular, evidence is provided of scholarship in the use of teaching logs within Mathematics Support tutorials which were found to be an invaluable tool in helping tutors to develop their teaching skills for supporting students' learning. The iterative process of engaging in analytical reflection of the learning and teaching process enables development of teaching strategies. As with other Mathematics Support interventions, evaluating the teaching improvement provided is difficult because standard evaluation methods such as portfolios and student learning cannot easily be applied. The support provided was ad hoc and does not follow a pre-planned programme of studies.

Along with this paper, there have recently been other moves towards improving the level of scholarship within the Mathematics Support community of practice (Croft, 2008; Samuels, 2007). It is hoped that these will not be isolated initiatives but that they will lead to a culture change within the community to increased scholarship in teaching and learning.

\section{References}

Atherton, J.S. (2005) Learning and teaching: reflection and reflective practice. York: The Higher Education Academy.

Bamforth, S.E., Robinson, C.L., Croft, A.C. and Crawford, A. (2007) 'Retention and progression of engineering students with diverse mathematical backgrounds', Teaching Mathematics and its Applications 26(4) pp 156-166.

Beveridge, I. (1993) The Minnesota model of developmental maths. ONLINE: http://www.sigma-cetl.ac.uk/index.php?section=97 (Accessed: 4 August 2009).

Beveridge, I. (1994) 'Assessing the value: maths workshop', Mathematics Support Association Newsletter 2 p 6. ONLINE: http://www.sigmacetl.ac.uk/index.php?section=82 (Accessed: 4 August 2009).

Beveridge, I. (1997) 'Survey: learning support for mathematics in FE and HE', Mathematics Support Association Newsletter 6 pp 20-23. ONLINE: http://www.sigma-cetl.ac.uk/index.php?section=85 (Accessed: 4 August 2009). 
Beveridge, I. (1999) 'A tale of two surveys', Mathematics Support Association Newsletter 9 pp 20-23. ONLINE: http://www.sigma-cetl.ac.uk/index.php?section=88 (Accessed: 4 August 2009).

Beveridge, I. and Bhanot, R. (1994) 'Maths support survey', Mathematics Support Association Newsletter 1 p 13. http://www.sigma-cetl.ac.uk/index.php?section=81 (Accessed: 4 August 2009).

Booth, D. (2003) 'The open learning resource centre at the University of Huddersfield', pp. 16-17, in MathsTEAM (ed.), Maths support for students. Birmingham: LTSN MathsTEAM Project.

Boyer, E.L. (1990) Scholarship reconsidered: priorities of the professoriate. New York: The Carnegie Foundation for the Advancement of Teaching.

Coleman, G. (2003) 'A review of the engineering maths first aid kit and the algebra refresher', pp. 44-45, in MathsTEAM (ed.) Maths support for students. Birmingham: LTSN MathsTEAM Project.

Cox, W. (2007) Practical, theory based principles for teaching mathematics in higher education. Mathematicians and mathematics educationalists: can we collaborate? ONLINE: http://www.maths.warwick.ac.uk/ mond/MVME/cox.pdf (Accessed: 4 August 2009).

Croft, A.C. (2008) 'Towards a culture of data collection an analysis in mathematics support centres', $3^{\text {rd }}$ Irish Workshop on Mathematics Learning and Support Centres: 'Is Mathematics Support Worthwhile?'. NUI Maynooth.

Croft, A.C. and Grove, M. (2006) 'Mathematics support: Support for the specialist mathematician and the more able student', MSOR Connections 6(2) pp 39-43.

Croft, A.C. and Stevenson, J. (2004) 'mathcentre and mathtutor - national mathematics support at the school/university transition', Mathematics TODAY, October, pp 164167. 
Dowling, D. and Nolan, B. (2006) 'Measuring the effectiveness of a maths learning support centre - the Dublin City University experience', CETL MSOR 2006 Conference, Loughborough.

Ellis, D. (2003) 'The study support centre: the Robert Gordon University, Aberdeen', pp. 14-15, in MathsTEAM (ed.) Maths support for students. Birmingham: LTSN MathsTEAM Project.

Entwistle, N. (2009) Teaching for understanding at university: deep approaches and distinctive ways of thinking. Basingstoke: Palgrave Macmillan.

Gill, O., O'Donoghue, J. and Johnson, P. (2008) An audit of mathematical support provision in Irish third level institutions. Limerick: CEMTL, University of Limerick.

Harrison, M., Beale, R., Foster, W.H., Gu, D.W. and Hibberd, S. (2006) 'The HELM transferability project', CETL-MSOR 2006 Conference. Loughborough.

Healey, M. (2000) 'Development of the scholarship of teaching in higher education: a discipline-based approach', Higher Education Research and Development 19(2) pp 169-189.

HEFCE (2004) Centres for Excellence in Teaching and Learning: invitation to bid for funds (January 2004/05). Bristol: Higher Education Funding Council for England.

Hu, C. and Samuels, P.C. (2007) 'Computer games and mobile technologies: Motivating students towards mathematics learning', CETL-MSOR 2007 Conference. Birmingham.

Kahn, P., Young, R., Grace, S., Pilkington, R., Rush, L., Tomkinson, B. and Willis, I. (2006) The role and effectiveness of reflective practices in programmes for new academic staff: A grounded practitioner review of the research literature. York: The Higher Education Academy.

Kreber, C. (2002) 'Teaching excellence, teaching expertise and the scholarship of teaching', Innovative Higher Education 27 pp 5-23. 
Lawson, D.A., Carpenter, S., and Croft, A.C. (2009) 'Mathematics support: real, virtual and mobile', International Journal of Technology in Mathematics Education 15(2).

Lawson, D.A., Croft, A.C. and Halpin, M. (2003) Good practice in thepProvision of mathematics support centres (2nd edn.). Birmingham: LTSN Maths, Stats and OR Network.

Lawson, D.A., Halpin, M. and Croft, A.C. (2001) 'After the diagnostic test - what next? Evaluating and enhancing the effectiveness of mathematics support centres', MSOR Connections 1(3) pp 19-23.

Lawson, D.A., Halpin, M. and Croft, A.C. (2002) After the diagnostic test - what next? Evaluating and enhancing the effectiveness of mathematics support centres - Part 2', MSOR Connections 2(1) pp 23-26.

Lawson, D.A., Symonds, R. and Samuels, P.C. (2006) 'Proactive interventions in mathematics and statistics support', CETL-MSOR 2006 Conference. Loughborough.

Loughborough University (2007) Postgraduate certificate in mathematics support and dyslexia/dyscalculia in FE/HE. ONLINE: http://pgcert.lboro.ac.uk/ (Accessed: 4 August 2009).

Loughborough University Mathematics Education Centre and Coventry University Mathematics Support Centre (2004) Centre for Excellence in Teaching and Learning stage 1 bid: A centre for excellence in the provision of university-wide mathematics and statistics support. Loughborough: Loughborough University.

MacGillivray, H. (2008) Learning support in mathematics and statistics in Australian universities - a guide for the university sector. Strawberry Hills: The Australian Learning and Teaching Council.

MathsTEAM (2003) Maths support for students. Birmingham: LTSN MathsTEAM Project. 
Patel, C. and Little, J. (2006) 'Measuring maths study support', International Journal of Mathematics and its Applications 25(3) pp 131-138.

Pell, G. and Croft, A.C. (2008) 'Mathematics support - support for all!', Teaching Mathematics and its Applications 27(4) pp 167-173.

Perkin, G. and Croft, A.C. (2004) 'Mathematics support centres - the extent of current provision', MSOR Connections 4(2) pp 14-18.

Roberts, G. (2002) SET for success: the supply of people with science, technology, engineering and mathematics skills. London: HM Treasury.

Samuels, P.C. (2006) 'Introducing the sigma mathematics support research programme', MSOR Connections 6(4) pp 12-13.

Samuels, P.C. (2007) 'Mathematics support as a practical discipline', CETL-MSOR 2007 Conference. Birmingham.

Saunders, M., Trowler, P., Ashwin, P., Machell, J., Williams, S. and Knight, P. (2007) The national evaluation of the CETL programme 2005-2010: first formative phase. Lancaster: CSET, Department of Educational Research, Lancaster University.

sigma Centre for Excellence in Mathematics and Statistics Support (2007) HEFCE CETL interim evaluation report. Coventry: Mathematics Education Centre, Loughborough University and Mathematics Support Centre, Coventry University.

Smith, K. and Gadsden, R. (2006) 'sigma SAS rescuing projects', CETL-MSOR 2006 Conference. Loughborough.

Staddon, E. and Newman, L. (2003) The education drop-in centre at the University of Glamorgan, pp. 22-23, in MathsTEAM (ed.) Maths support for students. Birmingham: LTSN MathsTEAM Project.

Thomas, J. W. (1993) 'Promoting independent learning in the middle grades: the role of instructional support practices', Elementary School Journal, 93(5) pp 575-591. 
Trott, C. (2003) 'Mathematics support for dyslexic and dyscalculic students' Patoss Bulletin 16(2) pp 22-28.

Wenger, E. (1998) Communities of practice: learning, meaning and identity. Cambridge: Cambridge University Press.

\section{Author details}

Dr Peter Samuels is Senior Research Fellow in the sigma Centre for Excellence in Mathematics and Statistics Support at Coventry University. His main research interests are mathematics support leadership, mathematics study skills and innovative uses of technology in mathematics support, especially serious games.

Chetna Patel is Manager of the Mathematics and Statistics Help Centre at the University of Sheffield. She has worked as a mathematics support centre manager for the last 12 years. Her main research interest is in the provision of extracurricular mathematics teaching. 